\title{
Cyclic plasticity and low cycle fatigue damage characterisation of thermally simulated X100Q heat affected zone
}

\author{
Ronan J. Devaney ${ }^{1,4, *}$, Heiner Oesterlin ${ }^{3}$, Padraic E. O’Donoghue ${ }^{2,4}$, and Sean B. Leen ${ }^{1,4}$ \\ ${ }^{1}$ Mechanical Engineering, College of Engineering and Informatics, NUI Galway, Ireland. \\ ${ }^{2}$ Civil Engineering, College of Engineering and Informatics, NUI Galway, Ireland. \\ ${ }^{3}$ Fraunhofer Institute for Mechanics of Materials IWM, Freiburg, Germany. \\ ${ }^{4}$ Ryan Institute for Environmental, Marine and Energy Research, NUI Galway, Ireland.
}

\begin{abstract}
This paper presents the cyclic plasticity and low cycle fatigue (LCF) damage characterisation of thermally simulated heat affected zone (HAZ) for API 5L X100Q weldments. Microstructures representative of the HAZ for two cooling rates are generated using a Gleeble thermomechanical simulator for manufacture of strain-controlled cyclic plasticity test specimens. The simulated HAZ specimens are subjected to a strain controlled test programme which examines the cyclic effects of strain-range and the tensile response at room temperature. A modified version of the Chaboche rate independent plasticity model, which accounts for early stage damage is implemented to characterise the cyclic plasticity response, including isotropic and kinematic hardening effects. The constitutive parameters are fitted to experimental data using an optimisation procedure developed within a MATLAB code. The measured response of the simulated HAZ specimens is compared to that of the X100Q parent material (PM), and the simulated HAZ is shown to share the early stage fatigue damage behaviour of the PM, but exhibits significantly a higher yield and cyclic strength.
\end{abstract}

\section{Introduction}

Steel catenary risers (SCRs) are pipelines used to conduct hydrocarbons or injection fluids between a production facility and a subsea wellhead. SCRs are subjected to heave caused by floating production facilities, vortex induced vibrations and cyclic pressurisation, making fatigue performance a primary concern. Weight reduction is also a key requirement for deep and ultra-deepwater SCRs. The use of next generation high strength steels facilitates a reduction in riser weight and installation time through the use of lower wall thickness pipe sections.

Welded connections are of particular concern for fatigue failure in SCRs [1]. The thermal cycles experienced during the welding process alter the microstructure and thus the constitutive and fatigue performance of the PM adjacent to the weld. The material and geometrical mismatch resultant from the welding process causes the welded connection to act as a fatigue hot-spot [2].

Mechanical characterisation of the HAZ is difficult due to its size and continuously changing nature from the fusion line to the unaffected PM. Ringinen et al. [3] used Gleeble thermomechanical simulation to generate HAZ material from the candidate SCR material X100. The microstructure and impact strength of the simulated HAZ material were compared to HAZ material obtained from welded joints, and the simulated HAZ material was shown to exhibit a representative microstructure, and an impact strength within the spread of the experimentally observed values for the HAZ material obtained from welded X100 joints.

Guiying and co-workers also used Gleeble thermomechanical simulation to generate HAZ specimens for an X100 grade steel, with peak temperatures and cooling rates representative of the coarse grain HAZ (CGHAZ), fine grain HAZ (FGHAZ) and intercritical HAZ (ICHAZ) [4]. The specimens were microstructurally examined and subjected to a tensile and impact test programme. The simulated ICHAZ was shown to exhibit a significantly reduced impact toughness relative to the PM and the other HAZ specimens. The tensile and yield strength of the simulated FGHAZ was lowest when compared to the PM and the other thermally transformed zones.

However, influence of the varied HAZ microstructure on the cyclic plasticity and fatigue performance has not been considered. This paper presents an experimental programme to characterise the tensile and LCF behaviour of X100Q PM and HAZ. Gleeble thermomechanical simulation is used to generate simulated HAZ specimens, with a peak temperature and cooling rates representative of the FGHAZ in the as-welded condition; post-weld heat treatment is typically avoided for offshore SCR welding due to the additional time required and associated costs. The simulated HAZ material is then used in a mechanical test programme, consisting of strain controlled room temperature tensile and LCF tests. The test programme results are used to fit a modified version of the Chaboche

\footnotetext{
* Corresponding author: r.devaney1@nuigalway.ie
} 
rate independent plasticity model using an optimisation procedure developed within a MATLAB code. The simulated HAZ specimens are shown to exhibit superior cyclic and tensile strength when compared to the parent material.

\section{Methodology}

\subsection{Experimental}

\subsubsection{HAZ thermal simulation}

The as-received $\mathrm{X} 100 \mathrm{Q}$ material is in the form of two $406.4 \mathrm{~mm}$ OD, $25 \mathrm{~mm}$ WT $2 \mathrm{~m}$ long seam welded pipe sections. The chemical composition supplied by the plate manufacturer is shown in Table 1.

Table 1. Chemical composition of the X100Q steel (\%wt).

\begin{tabular}{|c|c|c|c|c|c|c|}
\hline $\mathbf{C}$ & $\mathbf{S i}$ & $\mathbf{M n}$ & $\mathbf{P}$ & $\mathbf{S}$ & $\mathbf{A l}$ & $\mathbf{B}$ \\
\hline 0.14 & 0.21 & 1.17 & 0.008 & 0.001 & 0.084 & 0.0025 \\
\hline $\mathbf{C r}$ & $\mathbf{C u}$ & $\mathbf{M o}$ & $\mathbf{N}$ & $\mathbf{N b}$ & $\mathbf{N i}$ & $\mathbf{T i}$ \\
\hline 0.32 & 0.01 & 0.3 & 0.004 & 0.027 & 0.02 & 0.005 \\
\hline
\end{tabular}

Thermal simulation of X100Q HAZ was conducted using a Gleeble 3150 thermomechanical simulator at Fraunhofer IWM, Freiburg, Germany. Cylindrical specimens $120 \mathrm{~mm}$ long with a $10 \mathrm{~mm}$ diameter were manufactured from the as-received material for HAZ thermal simulation as shown in Figure 1. A $16 \mathrm{~mm}$ long gauge length of uniform thermal history was calibrated for each cooling rate by using a specimen with three type $\mathrm{K}$ thermocouples spot-welded, one at the centre of the specimen, one offset $5 \mathrm{~mm}$ from the centre of the specimen and a third thermocouple offset $8 \mathrm{~mm}$ from the centre of the specimen. Temperature control was achieved through a closed loop feedback system based on the temperature at the central thermocouple and the specimens were resistance heated and cooled using a combination of conduction through water cooled copper grips and air blasting.

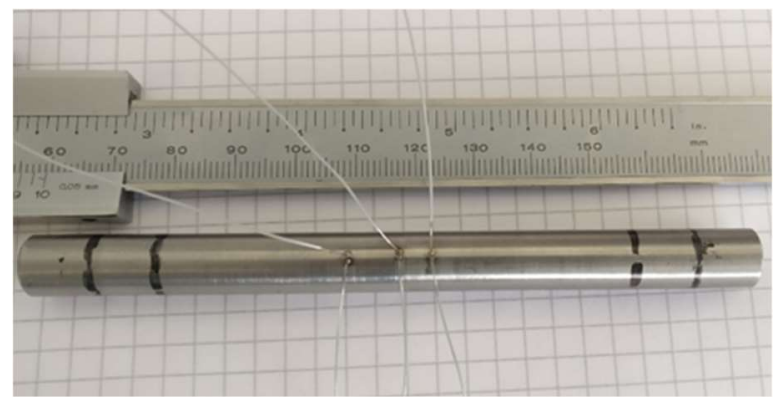

Figure 1. An X100Q specimen with type K thermocouples spot welded for Gleeble thermomechanical simulation.
Two thermal cycles in the expected range for the FGHAZ were identified for the thermomechanical simulation of HAZ specimens. For both cycles the specimens were heated at a rate of $100^{\circ} \mathrm{C} / \mathrm{s}$ above the $\mathrm{Ac}_{3}$ temperature of $847^{\circ} \mathrm{C}$ to a peak of $950^{\circ} \mathrm{C}$. The peak temperature was maintained for 0.5 seconds before the specimens were cooled to $110^{\circ} \mathrm{C}$ at rates of $10^{\circ} \mathrm{C} / \mathrm{s}$ and $30^{\circ} \mathrm{C} / \mathrm{s}$.

\subsubsection{Microstructural analysis}

Microscopy specimens were manufactured from the asreceived material and the post-test Gleeble specimens, mounted in epoxy resin, then ground and polished to a $0.06 \mu \mathrm{m}$ finish using a diamond suspension and etched using Vilella's reagent. Microscopy was performed using an Olympus BX51M optical microscope at NUI Galway. Optical micrographs of the PM and two simulated HAZ microstructures are shown in Figure 2. The microstructure of the PM consisted of lower bainite with visible prior austenite grain boundaries (PAGBs) within which are sheaves of bainite consisting of bainitic ferrite (BF) laths separated by carbides. There was a visible reduction in grain size for the $10^{\circ} \mathrm{C} / \mathrm{s}$ simulated $\mathrm{HAZ}$ which exhibited an upper bainite microstructure also with visible BF laths and PAGBs. The $30^{\circ} \mathrm{C} / \mathrm{s}$ simulated $\mathrm{HAZ}$ displayed the greatest deviation from the $\mathrm{PM}$, with a granular bainite microstructure consisting of equiaxed $\mathrm{BF}$ and retained austenite (RA).
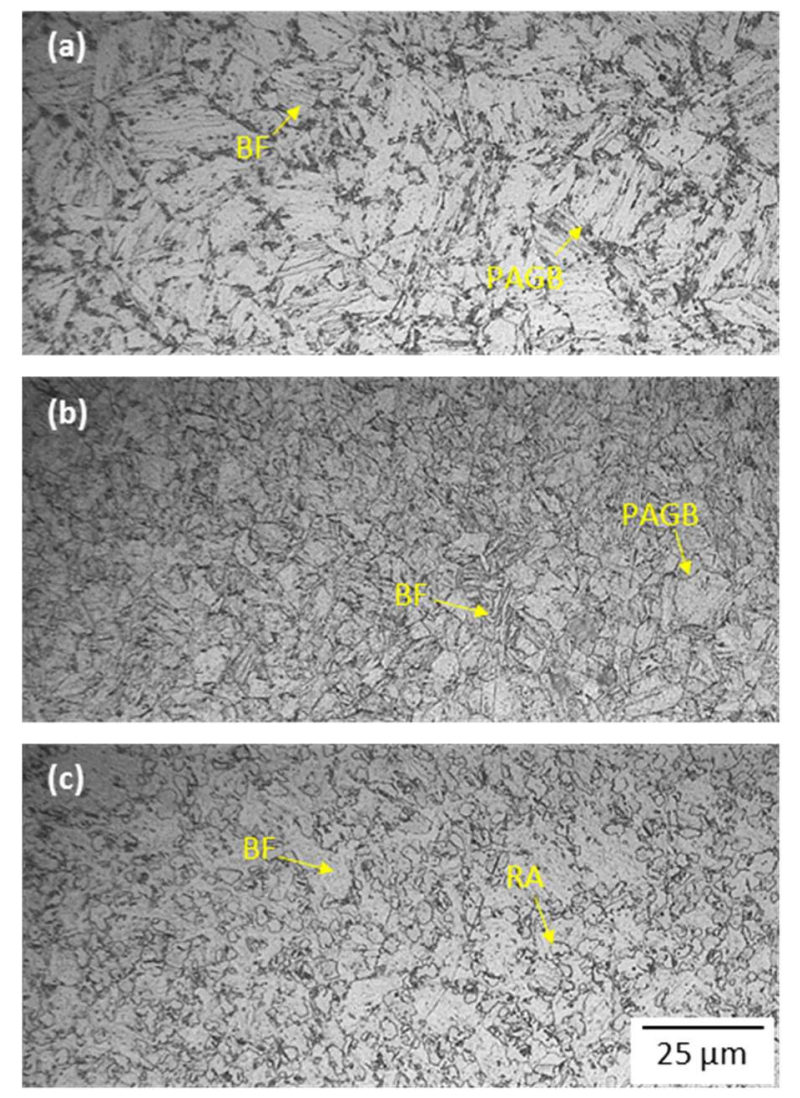

Figure 2. Optical micrographs of (a) X100Q PM, (b) $10^{\circ} \mathrm{C} / \mathrm{s}$ simulated HAZ and (c) $30^{\circ} \mathrm{C} / \mathrm{s}$ simulated HAZ. Microstructural features are labelled in yellow. 


\subsubsection{Tensile testing}

Tensile specimens were machined from the Gleeble simulated HAZ specimens, with a gauge length of $36 \mathrm{~mm}$, a diameter of $\varnothing 6 \mathrm{~mm}$ and an average surface roughness of $0.2 \mu \mathrm{m}$ on the gauge length. The specimens were machined with M10 threaded ends.

\subsubsection{Cyclic testing}

LCF specimens were prepared from the as-received X100Q and the Gleeble simulated HAZ specimens. The PM LCF specimen were machined to a gauge length and diameter of $16 \mathrm{~mm}$ and $\varnothing 6.5 \mathrm{~mm}$ respectively, while the HAZ specimen are machined to a gauge length and diameter of $12 \mathrm{~mm}$ and $\varnothing 7 \mathrm{~mm}$ respectively. All LCF specimens are polished to an average surface roughness of $0.2 \mu \mathrm{m}$ on the gauge length.

\subsection{Modelling}

\subsubsection{Constitutive model}

A damage mechanics methodology is used during constitutive modelling, where damage is modelled as an effective reduction in load resisting area due to the formation and coalescence of micro voids within the material. The experimentally observed early stage damage in X100Q PM highlighted by Devaney et al. [5] is accounted for by including the effects of damage when modelling the constitutive response of the materials. The damage accumulation is experimentally measured throughout each LCF test using the following equation

$$
D_{\mathrm{N}}=1-\frac{E_{\mathrm{N}}}{E_{0}}
$$

where $D_{\mathrm{N}}$ is the level of damage at cycle N, $E_{0}$ is the initial elastic modulus and $E_{\mathrm{N}}$ is the unloading modulus at cycle N. Using this definition of damage and the assumption of isotropic damage, the effective stress is defined as

$$
\tilde{\sigma}=\frac{\sigma S}{S-S_{\mathrm{D}}}=\frac{\sigma}{1-D}=E \varepsilon^{\mathrm{e}}
$$

where $\tilde{\sigma}$ is effective stress, $S$ is the area of load resisting material on a plane perpendicular to the applied load, $S_{\mathrm{D}}$ is the area of voids a plane perpendicular to the applied load and $\varepsilon^{\mathrm{e}}$ is elastic strain. The yield function for the Chaboche time independent nonlinear kinematicisotropic hardening (NLKIH) plasticity model with damage is

$$
f=\left(\frac{\boldsymbol{\sigma}}{1-D}-\chi\right)_{\mathrm{eq}}-r-k
$$

where $f$ is the yield function, $\boldsymbol{\sigma}$ is the stress tensor, $\chi$ is the kinematic back stress tensor, eq denotes von Mises equivalent stress, $r$ is the isotropic hardening/softening and $k$ is the cyclic yield stress. The increment in plastic strain is calculated as follows

$$
\dot{\boldsymbol{\varepsilon}}^{\mathrm{p}}=\dot{\lambda} \frac{d f}{d \boldsymbol{\sigma}}=\frac{3}{2} \frac{\dot{\lambda}}{1-D} \frac{\left(\frac{\boldsymbol{\sigma}}{1-D}-\chi\right)_{\mathrm{dev}}}{\left(\frac{\boldsymbol{\sigma}}{1-D}-\chi\right)_{\mathrm{eq}}}
$$

where $\dot{\boldsymbol{\varepsilon}}^{\mathrm{p}}$ is the increment in the plastic strain tensor, $\dot{\lambda}$ is the plastic multiplier, and dev denotes deviatoric stress. The Armstrong-Frederick nonlinear kinematic hardening evolution with damage for each back stress is as follows

$$
\dot{\chi}_{\mathrm{i}}=\frac{2}{3} C_{\mathrm{i}} \dot{\mathbf{\varepsilon}}^{\mathrm{p}}(1-D)-\gamma_{\mathrm{i}} \chi_{\mathrm{i}} \dot{p}
$$

where $\dot{\chi}_{\mathrm{i}}$ is the increment in back stress tensor, $\chi_{\mathrm{i}}$ is the back stress tensor, $C_{\mathrm{i}}$ are hardening moduli and $\gamma_{\mathrm{i}}$ are recall parameters, also $\chi=\sum_{i=1}^{3} \chi_{i}$. The increment in Chaboche nonlinear isotropic kinematic hardening/softening is given as

$$
\dot{r}_{\mathrm{i}}=b_{\mathrm{i}} Q_{\mathrm{i}}(1-D) \dot{p}-b_{\mathrm{i}} r_{\mathrm{i}} \dot{p}
$$

where $\dot{r}_{\mathrm{i}}$ is the isotropic hardening/softening increment, $r_{\mathrm{i}}$ is the level of isotropic hardening/softening, $Q_{\mathrm{i}}$ is the saturated hardening/softening stress and $b_{\mathrm{i}}$ controls the rate of hardening/softening, also $r=\sum_{\mathrm{i}=1}^{2} r_{\mathrm{i}}$.

\section{Results}

\subsection{Experimental}

\subsubsection{HAZ thermal simulation}

Typical examples of the agreement shown between the chosen simulated HAZ thermal cycles and the thermal cycles measured from the central thermocouple on the Gleeble specimen for both the $10^{\circ} \mathrm{C} / \mathrm{s}$ cooling rate and the $30^{\circ} \mathrm{C} / \mathrm{s}$ are shown in Figure 3. The effect of the latent heat released during the bainite transformation is visible in the $30^{\circ} \mathrm{C} / \mathrm{s}$ cooling curve. From these results the average $\mathrm{Ar}_{3}$ temperature for the $30^{\circ} \mathrm{C} / \mathrm{s}$ and $10^{\circ} \mathrm{C} / \mathrm{s}$ cooling rates can be estimated as $380^{\circ} \mathrm{C}$ and $413^{\circ} \mathrm{C}$ respectively.

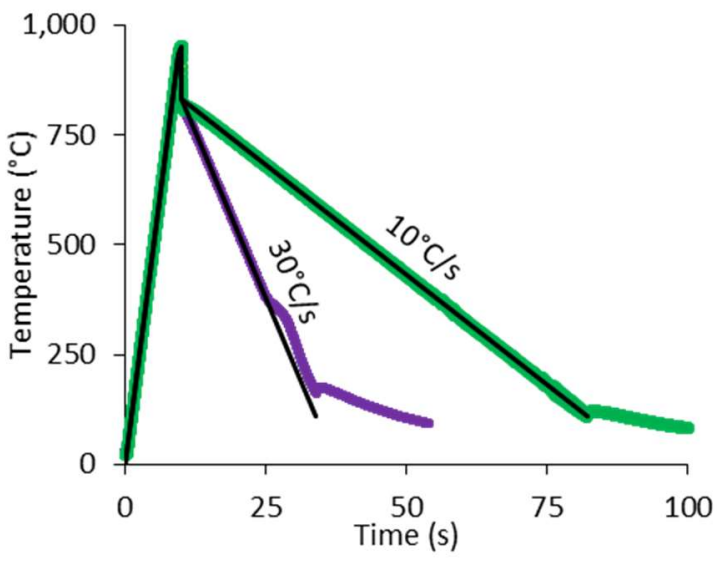

Figure 3. A comparison between the desired thermal cycles and the thermal cycles measured from the central thermocouple achieved during Gleeble thermal simulation of HAZ material. 


\subsubsection{Tensile testing}

The stress-strain tensile response of both the $10^{\circ} \mathrm{C} / \mathrm{s}$ and the $30^{\circ} \mathrm{C} / \mathrm{s}$ simulated $\mathrm{HAZ}$ specimen is shown in Figure 4 , and an image of a post-test tensile specimen is shown in Figure 5. On either side of the homogeneous HAZ region, an interface zone (IF) exists in which there is a gradation in microstructure (and presumably therefore mechanical behaviour) from those of the HAZ to those of the PM. In act, this is the observed location of significant necking and tensile failure for both specimen. Otherwise, it can be seen that the higher cooling rate leads to a harder response and a higher ductility. This can perhaps be attributed to the more refined microstructure of this case shown in Figure 2 (c). However, this requires further investigation, for example, using the through-process modelling methodology [6] under development within the present Science Foundation Ireland (SFI) project "Multiscale, through-process characterisation for nextgeneration welded connections" (MECHANNNICS), in order to quantitatively assess the effects of the gradation in microstructure in the IF zone. Real joints will inevitably contain such IF regions also and, indeed, these are common locations of failure, which has motivated this work.

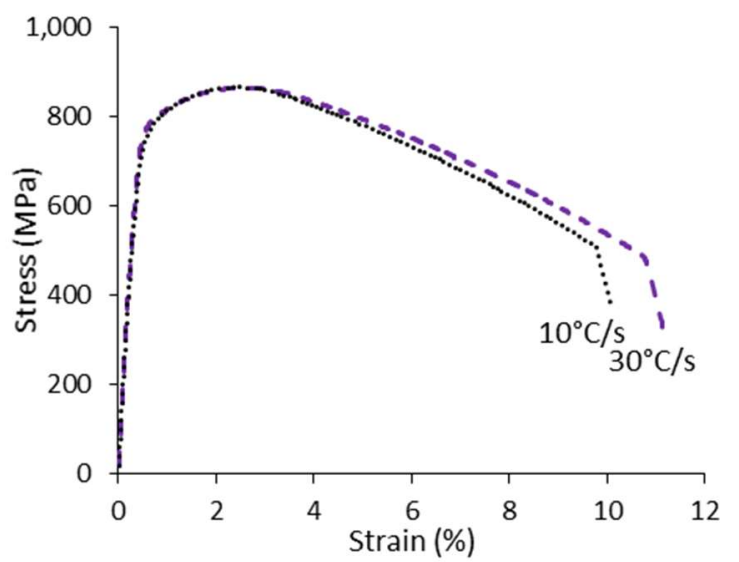

Figure 4. The stress-strain tensile response of the simulated HAZ specimens.

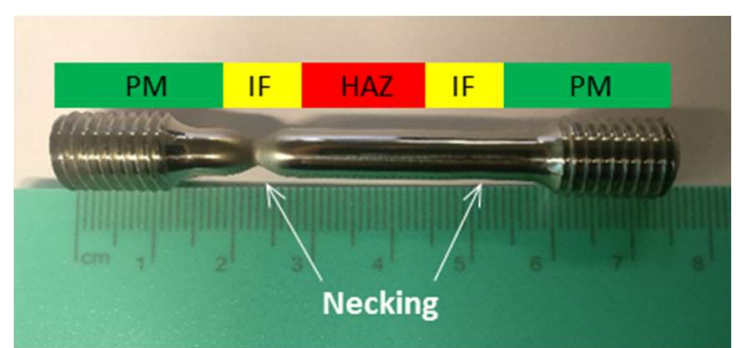

Figure 5. A post-test simulated HAZ tensile specimen tensile specimen, showing necking at the IF regions. The unaffected PM, IF zone and thermally calibrated region of simulated HAZ is shown schematically.

\subsubsection{Cyclic testing}

A comparison of the measured stress-strain response of the PM and the $10^{\circ} \mathrm{C} / \mathrm{s}$ simulated HAZ for the $1^{\text {st }}$ cycle of a $\Delta \varepsilon=1 \%$ strain controlled test is shown in Figure 6 . The onset of yield for the simulated HAZ specimen occurs at approximately $100 \mathrm{MPa}$ higher than for the PM, and the stress amplitude of the simulated HAZ is about $146 \mathrm{MPa}$ or $18 \%$ greater than the PM over the $1^{\text {st }}$ cycle. There is also a significant contrasting response in terms of hardening-softening behaviour of the HAZ and PM materials; the simulated HAZ cyclically hardens within the first cycle, by approximately $15 \mathrm{MPa}$, whereas the PM softens by approximately $5 \mathrm{MPa}$.

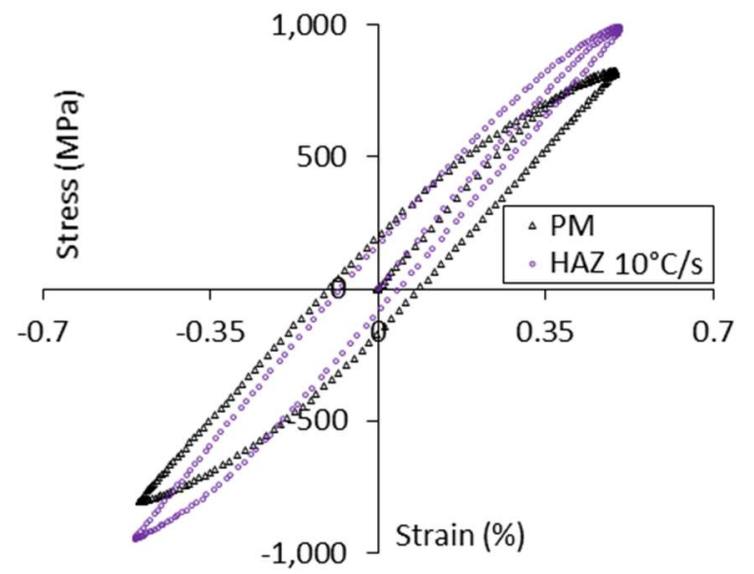

Figure 6. A comparison between the first cycle stress-strain responses of the $10^{\circ} \mathrm{C} / \mathrm{s} \mathrm{HAZ}$ and the $\mathrm{PM}$ at a $1 \%$ strain range.

The measured damage evolution of the $10^{\circ} \mathrm{C} / \mathrm{s}$ simulated HAZ for a $\Delta \varepsilon=1 \%$ test is compared to that of the PM in Figure 7. The early stage damage for each test was observed through the degradation in unloading modulus as shown in Eq 1. The same general trend in damage evolution can be seen for the initial cycles of both the PM and the HAZ, with a rapid rise for the first couple of cycles before exhibiting stabilisation. The $10^{\circ} \mathrm{C} / \mathrm{s}$ simulated HAZ LCF specimen failed through buckling in the IF zone after 7 cycles for the $\Delta \varepsilon=1 \%$ test.

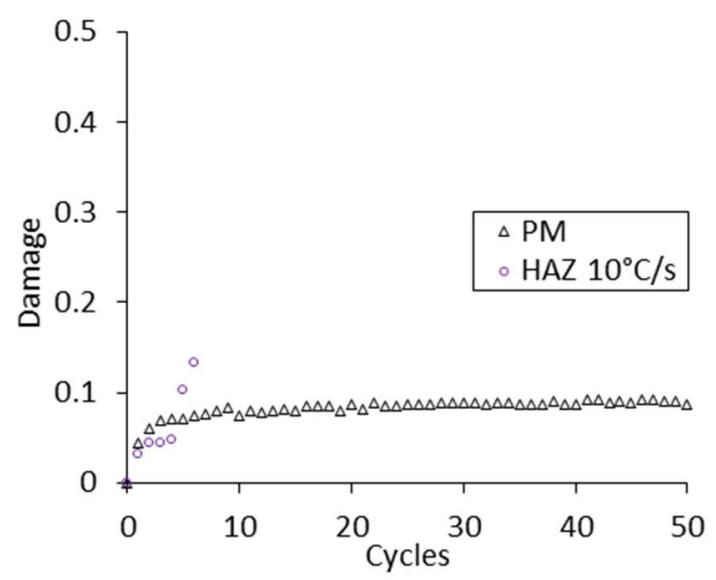

Figure 7. A comparison between the experimentally measured damage evolutions for the $10^{\circ} \mathrm{C} / \mathrm{s} \mathrm{HAZ}$ and the PM at a $1 \%$ strain range.

Figure 8 shows a comparison between the first cycle stress-strain responses of the simulated HAZ and the PM for the $\Delta \varepsilon=0.8 \%$ test. The stress amplitude for the first cycle of the $\Delta \varepsilon=0.8 \%$ simulated HAZ test is $85 \mathrm{MPa}$ greater than the PM. Both materials exhibit hardening over the first cycle, but the extent of hardening in the 
simulated $\mathrm{PM}$ is almost negligible in comparison to that of the $10^{\circ} \mathrm{C} / \mathrm{s}$ simulated HAZ. A comparison of the measured damage evolutions for the $10^{\circ} \mathrm{C} / \mathrm{s}$ simulated $\mathrm{HAZ}$ and the PM for the $\Delta \varepsilon=0.8 \%$ test is shown in Figure 9. The damage level in the simulated HAZ matches that of the PM at a value of approximately 0.05 for the majority of life, then increases slightly in the cycles preceding failure.

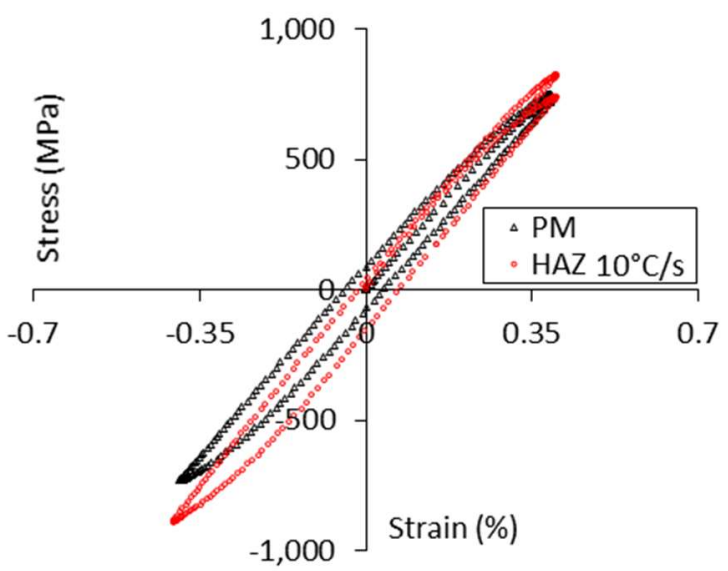

Figure 8. A comparison between the first cycle stress-strain responses of the $10^{\circ} \mathrm{C} / \mathrm{s} \mathrm{HAZ}$ and the $\mathrm{PM}$ at a $0.8 \%$ strain range.

For the $\Delta \varepsilon=0.6 \%$ test the stress-strain response for both the $10^{\circ} \mathrm{C} / \mathrm{s}$ simulated $\mathrm{HAZ}$ and the $\mathrm{PM}$ is predominantly elastic. As a result, the stress amplitude of the simulated HAZ is just $37 \mathrm{MPa}$ greater than the PM for the first cycle, as shown in Figure 10, and both the simulated HAZ and the PM show a low levels of hardening, with the extent of hardening greater in the simulated HAZ specimen.

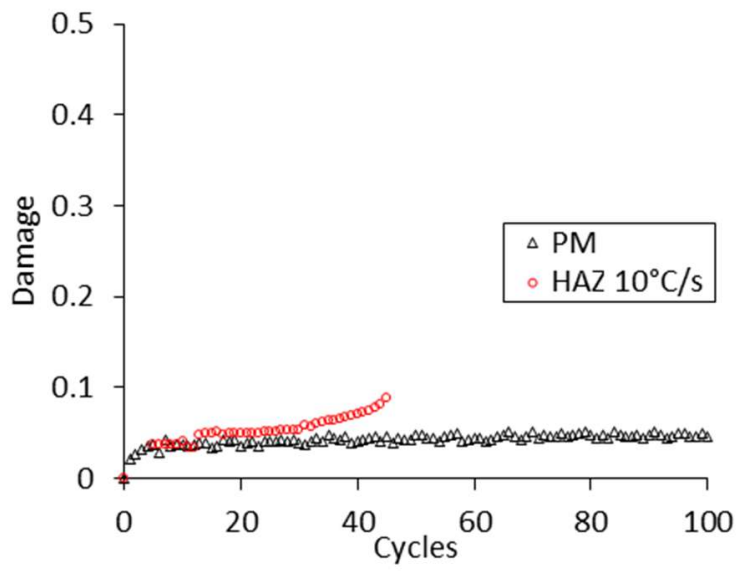

Figure 9. A comparison between the experimentally measured damage evolutions for the $10^{\circ} \mathrm{C} / \mathrm{s} \mathrm{HAZ}$ and the $\mathrm{PM}$ at a $0.8 \%$ strain range.

Figure 11 shows a comparison of the measured damage evolutions for the $10^{\circ} \mathrm{C} / \mathrm{s}$ simulated $\mathrm{HAZ}$ and the PM for the $\Delta \varepsilon=0.6 \%$ test. Both materials follow the same trend of a rapid rise in damage within the first few cycles followed by stabilisation, but the stabilised level of early stage damage in the $10^{\circ} \mathrm{C} / \mathrm{s}$ simulated $\mathrm{HAZ}$ prior to the onset of failure is greater than that of the PM.

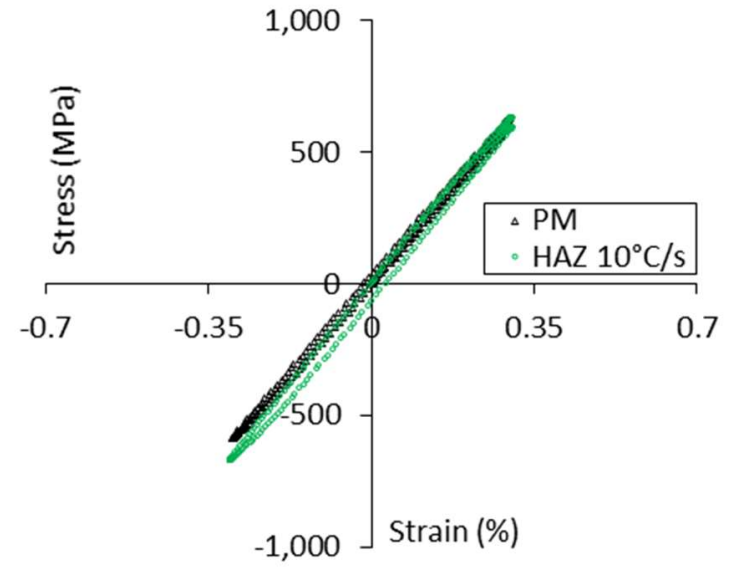

Figure 10. A comparison between the first cycle stress-strain responses of the $10^{\circ} \mathrm{C} / \mathrm{s} \mathrm{HAZ}$ and the $\mathrm{PM}$ at a $0.6 \%$ strain range.

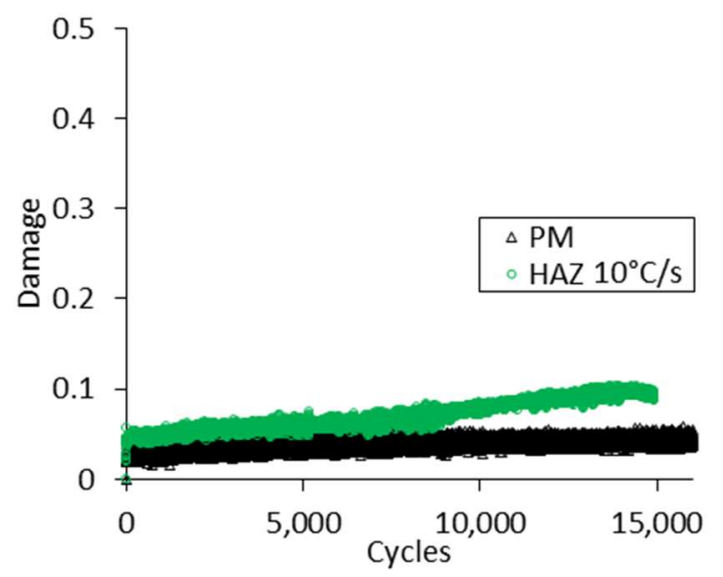

Figure 11. A comparison between the experimentally measured damage evolutions for the $10^{\circ} \mathrm{C} / \mathrm{s} \mathrm{HAZ}$ and the $\mathrm{PM}$ at a $0.6 \%$ strain range.

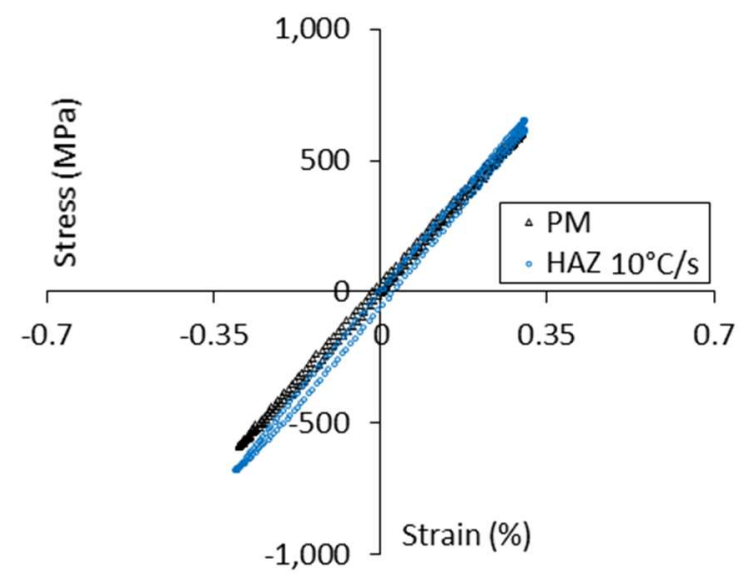

Figure 12. A comparison between the first cycle stress-strain responses of the $30^{\circ} \mathrm{C} / \mathrm{s} \mathrm{HAZ}$ and the $\mathrm{PM}$ at a $0.6 \%$ strain range.

Figure 12 shows a comparison of the first cycle stress-strain responses for the $30^{\circ} \mathrm{C} / \mathrm{s}$ simulated $\mathrm{HAZ}$ and the PM. The stress amplitude of the $30^{\circ} \mathrm{C} / \mathrm{s}$ simulated $\mathrm{HAZ}$ is approximately $50 \mathrm{MPa}$ greater than the $\mathrm{PM}$ and $14 \mathrm{MPa}$ greater than the $10^{\circ} \mathrm{C} / \mathrm{s}$ simulated $\mathrm{HAZ}$, indicating that the higher cooling rate has resulted in the formation of a harder HAZ material.

The increased hardness and therefore reduction in cyclic plasticity for the $30^{\circ} \mathrm{C} / \mathrm{s}$ simulated $\mathrm{HAZ}$ specimen is also indicated by the lower level of stabilised early stage 
damage exhibited for the $\Delta \varepsilon=0.6 \%$ test when compared to the $\mathrm{PM}$ or the $10^{\circ} \mathrm{C} / \mathrm{s}$ simulated $\mathrm{HAZ}$, as shown in Figure 13. This suggests that the early stage damage observed for the PM and simulated HAZ is a function of cyclic plasticity, which has long been recognised as the primary mechanism in fatigue failure [7].

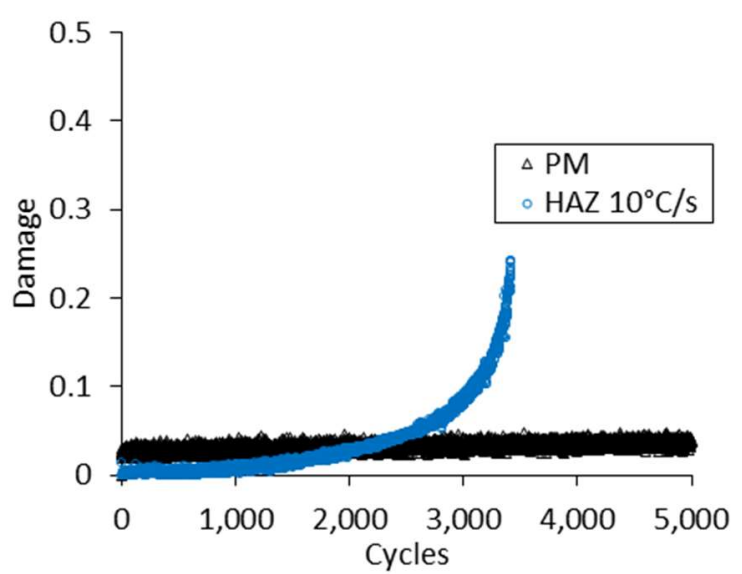

Figure 13. A comparison between the experimentally measured damage evolutions for the $30^{\circ} \mathrm{C} / \mathrm{s} \mathrm{HAZ}$ and the PM at a $0.6 \%$ strain range.

During cyclic testing of the simulated HAZ specimens it was noted that the significant change in the mechanical response of heat treated gauge length resulted in a concentration of deformation in the IF zone between the thermally calibrated region of simulated HAZ and the unaffected PM. Similar to the tensile specimens, cyclic failure is also generally found to occur in the IF zones, as shown schematically in Figure 15. Figure 15 (a) shows an example of a buckling failure in the IF zone and Figure 15 (b) shows a fracture failure in the IF zone.

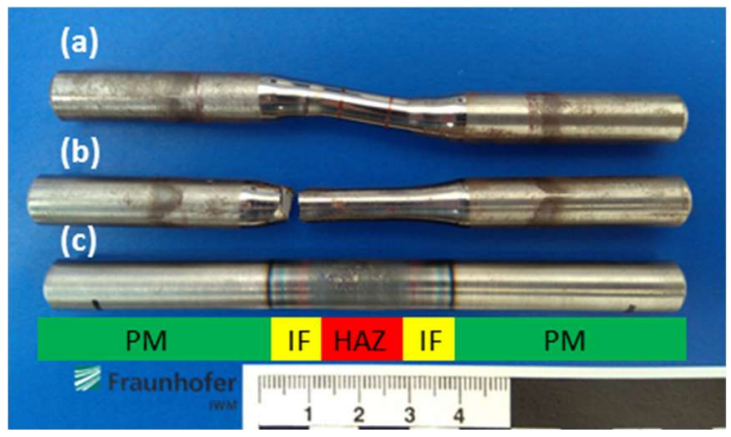

Figure 14. (a) Buckled simulated HAZ LCF test specimen. (b) Simulated HAZ LCF test specimen with failure outside the heat treated gauge length. (c) Gleeble simulated HAZ specimen posttest. The unaffected PM, IF zone and thermally calibrated region of simulated HAZ is shown schematically.

\subsection{Modelling}

\subsubsection{Constitutive model}

A typical example of the fit to the first cycle and stabilised stress-strain response achieved using the Chaboche NLKIH constitutive model with parameter optimisation accounting for damage is shown in Figures 15 and 16 for the $\Delta \varepsilon=1 \% 10^{\circ} \mathrm{C} / \mathrm{s}$ simulated HAZ specimen. For both cycles the predicted stress-range of the model is within $4.5 \%$ of the experimental observations.

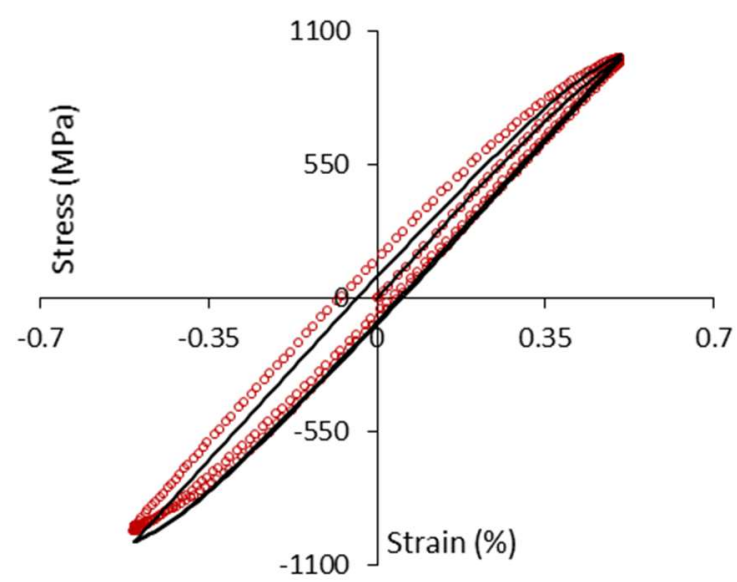

Figure 15. The fit between the model (black line) and the experimental (open symbols) stress-strain response for the first cycle of the $\Delta \varepsilon=1 \% 10^{\circ} \mathrm{C} / \mathrm{s}$ simulated $\mathrm{HAZ}$ specimen test.

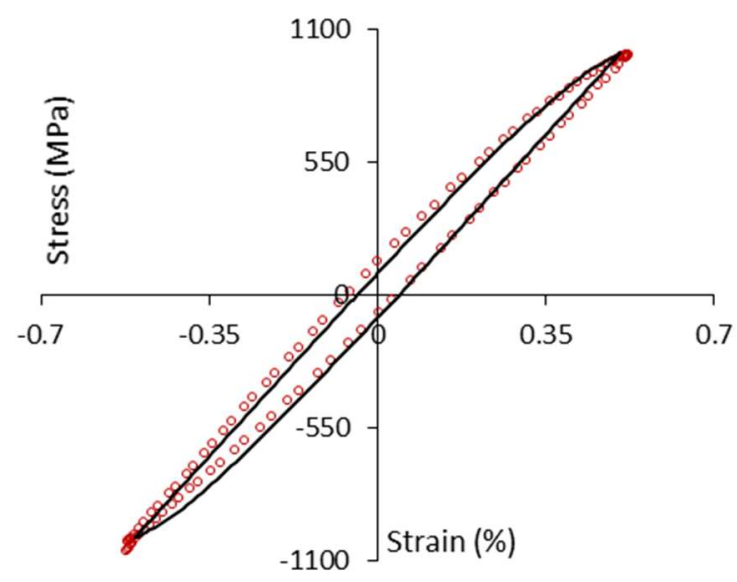

Figure 16. The fit between the model (black line) and the experimental (open symbols) stress-strain response for a stabilised cycle of the $\Delta \varepsilon=1 \% 10^{\circ} \mathrm{C} / \mathrm{s}$ simulated HAZ specimen test.

Table 2 shows the NLKIH parameters identified for the X100Q PM and $10^{\circ} \mathrm{C} / \mathrm{s}$ simulated $\mathrm{HAZ}$ from the parameter optimisation process accounting for damage, as described by the authors in [5]. The increased hardness of the simulated HAZ material can be seen from the increase in the cyclic yield stress, while the difference in the cyclic response is most apparent when comparing the significant level of isotropic softening exhibited by the PM to the low level of cyclic hardening displayed by the $10^{\circ} \mathrm{C} / \mathrm{s}$ simulated HAZ. 
Table 2. The optimised NLKIH parameters for the X100Q PM and $10^{\circ} \mathrm{C} / \mathrm{s}$ simulated $\mathrm{HAZ}$.

\begin{tabular}{|c|c|c|}
\hline & $\mathbf{P M}$ & $\mathbf{1 0}^{\circ} \mathbf{C} / \mathbf{s} \mathbf{H A Z}$ \\
\hline $\boldsymbol{E}$ (GPa) & 209.8 & 217.8 \\
\hline $\boldsymbol{k}$ (MPa) & 279.5 & 420.6 \\
\hline $\boldsymbol{b} \mathbf{1 , 2}$ & 0.0104 & 4050 \\
& 0.3912 & 21335 \\
\hline \multirow{2}{*}{$\mathbf{1 , 2}(\mathbf{M P a})$} & -181.8 & 50 \\
& -68.2 & 20 \\
\hline \multirow{2}{*}{$\boldsymbol{1}_{\mathbf{1 , 2 , 3}}(\mathbf{G P a})$} & 1200.7 & 2342.9 \\
& 360 & 364.6 \\
& 94.7 & 10.7 \\
\hline & 4562.3 & 6478.5 \\
$\boldsymbol{\gamma}_{\mathbf{1}, \mathbf{2}, \mathbf{3}}$ & 2858.7 & 3180.5 \\
& 32.7 & 32 \\
\hline
\end{tabular}

\section{Discussion}

The two distinct microstructures and related sets of mechanical properties obtained from the PM during the HAZ simulation test programme highlight the importance of controlling cooling rate for welding in SCRs, where it is typically desirable to avoid the requirement for post weld heat treatments due to the high costs associated with offshore installation resources. The bainitic transformation temperatures observed through the liberation of latent heat from the simulated HAZ specimen were below the value of $518^{\circ} \mathrm{C}$ reported by Wang et al. [8] for an X100Q steel. It is likely that this difference is partially caused by the slower cooling rate of $5^{\circ} \mathrm{C} / \mathrm{s}$ as it has been shown by Qiao and co-workers[9] and indicated by the results reported here, that the transformation temperature decreases with an increase in cooling rate. The increased accuracy of measurements taking using dilatometry will also result in an earlier detection of transformation temperature.

The present work has permitted identification of the cyclic plasticity and early stage LCF damage of thermally simulated FGHAZ material. This is a key step forward for modelling and design of multi-material welded X100Q connections where HAZ behaviour is a key challenge, due to the typically small size-scale of HAZ, and the associated difficulty of manufacturing tensile and fatigue test specimens. As mentioned above, the present work is part of a larger programme of research (the MECHANNICS project, funded by SFI), which is developing multi-scale, through-process predictive methodologies for welded materials and joints. Hence, a key next step for X100Q, is the application of this through-process methodology developed in the MECHANNICS project, e.g. see Mac Ardghail et al. [6], to the present X100Q, specifically for the IF zone. This will facilitate more detailed analysis of the failure behaviour of the microstructure-gradient IF zones, which are so important for fatigue failure, as also demonstrated here. This issue has been most documented for "Type IV cracking" high temperature creep failures in $9 \mathrm{Cr}$ power plant steel welds [10]. The concentration of failures in this region is due to its susceptibility for partial transformation to austenite and over-tempering of the PM as a result of the thermal cycles experienced.

From the cyclic plasticity constitutive behaviour obtained for the $10^{\circ} \mathrm{C} / \mathrm{s}$ simulated $\mathrm{HAZ}$ specimen for the initial and stabilised cycles, it was possible to demonstrate that the material shared the early stage damage behaviour of the PM which has been attributed to the formation of micro cracks within the material as discussed by the authors in [5].

\section{Conclusions}

Two simulated HAZ microstructures representative of the FGHAZ in X100Q welds have been generated using Gleeble thermomechanical simulation. On microstructural examination the $10^{\circ} \mathrm{C} / \mathrm{s}$ simulated $\mathrm{HAZ}$ exhibited an upper bainite microstructure, while the $30^{\circ} \mathrm{C} / \mathrm{s}$ simulated HAZ showed a granular bainite microstructure, in contrast to the lower bainite microstructure of the PM.

The simulated HAZ specimens were subjected to a room temperature LCF and tensile test programme where the constitutive, cyclic plasticity and early stage damage behaviour was observed. During the LCF and tensile test programme a soft material region was identified at the interface of the simulated HAZ material and the parent metal in which all failures occurred. The softening of the material in this region is attributed to a combination of partial transformation to austenite and over tempering of the parent material.

The combined application of the NLKIH constitutive model with damage and MATLAB parameter optimisation process which accounts for early stage experimental damage model allows identification from the experimentally observed cyclic plasticity response of the $10^{\circ} \mathrm{C} / \mathrm{s}$ simulated HAZ. Future work will focus on quantitative analysis and investigation of the IF zone, for example, using the through-process methodology of the MECHANNICS project.

This publication has emanated from research conducted with the financial support of Science Foundation Ireland as part of the MECHANNICS joint project between NUI Galway and University of Limerick under Grant Number SFI/14/IA/2604.

The authors would also like to thank Eva Augenstein of Fraunhofer IWM.

\section{References}

[1] M. Abelanet, D. Karunakaran, R. Jones, S. Eyssautier, and P. White, "Deepwater steel catenary risers require attention to fatigue factors," Offshore magazine, no. 10. Oct-2013.

[2] R. J. Devaney, P. E. O’Donoghue, and S. B. Leen, "Global and local fatigue analysis of X100 \& X60 steel catenary riser girth welds," J. Struct. Integr. Maint., vol. 2, no. 3, pp. 181-189, Jul. 2017. 
[3] D. A. Ringinen, A. V Chastukhin, G. E. Khadeev, L. I. Efron, and P. P. Stepanov, "A WELDABILITY STUDY OF STEEL OF STRENGTH CLASS X100," Metallurgist, vol. 57, no. 12, pp. 68-74, 2013.

[4] Q. Guiying, Z. Ming, G. U. Yu, H. A. N. Xiulin, W. Xu, X. Furen, and L. Bo, "Mechanical Properties of the Heat Affected Zone of an X100 Grade Pipeline Steel," in Advances in Materials and Processing Technologies XV, 2014, pp. 795802.

[5] R. J. Devaney, P. E. O’Donoghue, and S. B. Leen, "Experimental characterisation and computational modelling for cyclic elasticplastic constitutive behaviour and fatigue damage of X100Q for steel catenary risers," Int. J. Fatigue, Under review, 2018.

[6] P. Mac Ardghail, N. Harrison, and S. B. Leen, "A through-process, thermomechanical model for predicting welding-induced microstructure evolution and post-weld high temperature fatigue response," Int. J. Fatigue, In press, 2018.

[7] J. Morrow, "Cyclic Plastic Strain Energy and Fatigue of Metals," in Internal Friction, Damping, and Cyclic Plasticity, 100 Barr Harbor Drive, PO Box C700, West Conshohocken, PA 19428-2959: ASTM International, 1965, pp. 4587.

[8] H. Wang, F. Wang, G. Shi, Y. Sun, J. Liu, Q. Wang, and F. Zhang, "Effect of quenching temperature on microstructure and yield strength of Q-T-treated X100Q bainitic steel," Mater. Res. Express, no. 475, pp. 560-564, Mar. 2018.

[9] Z. X. Qiao, Y. C. Liu, L. M. Yu, and Z. M. Gao, "Formation mechanism of granular bainite in a 30CrNi3MoV steel," J. Alloys Compd., vol. 475, no. 1-2, pp. 560-564, 2009.

[10] J. A. Francis, W. Mazur, and H. K. D. H. Bhadeshia, "Review Type IV cracking in ferritic power plant steels," Mater. Sci. Technol., vol. 22, no. 12, pp. 1387-1395, Dec. 2006. 